\title{
Delayed hemorrhage after cold and hot snare resection of colorectal polyps: a multicenter randomized trial (interim analysis)
}

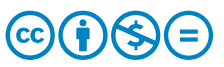

\section{Authors}

Masato Aizawa ${ }^{1}$, Kenichi Utano ${ }^{1}$, Takuya Tsunoda ${ }^{2}$, Osamu Ichii ${ }^{3}$, Takashi Kato ${ }^{4}$, Yasuyuki Miyakura ${ }^{5}$, Mitsuru Saka ${ }^{6}$, Daiki Nemoto ${ }^{1}$, Noriyuki Isohata ${ }^{1}$, Shungo Endo ${ }^{1}$, Yutaka Ejiri ${ }^{3}$, Alan Kawarai Lefor ${ }^{7}$, Kazutomo Togashi ${ }^{1}$

Institutions

1 Department of Coloproctology, Aizu Medical Center Fukushima Medical University, Fukushima, Japan

2 Department of Gastroenterology, Takeda General Hospital, Fukushima, Japan

3 Department of Gastroenterology, Fukushima Rosai Hospital, Fukushima, Japan

4 Department of Gastroenterology, Hokkaido Gastroenterology Hospital, Hokkaido, Japan

5 Department of Surgery, Saitama Medical Center Jichi Medical University, Saitama, Japan

6 Department of Gastroenterology, Fujita General Hospital, Fukushima, Japan

7 Department of Surgery, Jichi Medical University, Shimotsuke, Japan

Bibliography

DOI https://doi.org/10.1055/a-0854-3561 |

Endoscopy International Open 2019; 07: E1123-E1129

(c) Georg Thieme Verlag KG Stuttgart · New York

eISSN 2196-9736

Corresponding author

Kazutomo Togashi, MD, PhD, Department of

Coloproctology, Aizu Medical Center Fukushima Medical

University, 21-2 Maeda, Tanisawa, Kawahigashi-machi,

Aizuwakamatsu-city, Fukushima 969-3492, Japan

Fax: +81-242752568

togashik@fmu.ac.jp

\section{ABSTRACT}

Background and study aims Delayed bleeding is believed to occur less frequently after cold snare polypectomy (CSP), but this has not been validated in clinical trials. This study aimed to compare rates of delayed bleeding after CSP and hot snare polypectomy (HSP).

Patients and methods We conducted a multicenter, randomized controlled trial. Participants scheduled to undergo endoscopic resection of colorectal polyps $\leq 10 \mathrm{~mm}$ were enrolled and randomly assigned to CSP or HSP. Prophylactic clipping was performed at the endoscopists' discretion. The primary outcome was delayed bleeding rate. Secondary outcomes included immediate bleeding rate and clipping rate. Sample size calculation showed that 451 patients were required in each arm.

Results At the end of the study period decided in advance, 308 participants were recruited and an interim analysis was performed. A total of 273 patients (mean age $62.2 \pm 8.8$ years; 188 males) were analyzed, with 139 patients allocated to CSP and 134 to HSP. In total, 367 polyps were resected with CSP and 360 polyps with HSP. There were no significant differences in patient demographics or polyp characteristics. In per-patient-based analysis, delayed bleeding rates were $0.7 \%$ after CSP and $0.7 \%$ after HSP. Per-polyp analysis showed similar results (CSP: $0.3 \%$ vs. HSP: $0.6 \%$ ). The immediate bleeding rate was significantly higher with CSP vs. HSP ( $54 \%$ vs. $14 \%, P<0.0001$ ), while clipping rates were $18 \%$ and $19 \%$, respectively.

Conclusion This interim analysis did not demonstrate that delayed bleeding after CSP is less frequent than after HSP. The delayed bleeding rate after HSP was lower than expected.

Meeting presentations: Digestive Disease Week 2017

University Hospital Medical Network Clinical Trials Registry UMIN000012520

TRIAL REGISTRATION: Multicenter randomized controlled trial UMIN000012520 at http://www.umin.ac.jp 


\section{Introduction}

Colonoscopic resection of adenomatous polyps is useful to prevent colorectal cancer progression based on the adenoma-carcinoma sequence, and reduces the colorectal cancer mortality rate $[1,2]$. Polypectomy using electrocautery, the so-called "hot polypectomy," is relatively safe but may cause polypectomy-related complications such as bleeding and perforation [3, 4]. There are numerous case series describing significant bleeding after hot snare polypectomy (HSP), which required surgical intervention. In a 1988 survey by the American Society for Gastrointestinal Endoscopy [5], 516 members performed 13,081 hot biopsy forceps resections (one type of hot resection), and $16 \%$ reported patients with significant complications such as bleeding, perforation, post-coagulation syndrome, or death.

Because cold snare polypectomy (CSP) for diminutive polyps was introduced in 1992 [6], colonoscopists advocate CSP due to shorter procedure time and a lower rate of complications, particularly delayed bleeding. Small polyps do not typically contain large blood vessels and delayed bleeding usually stops spontaneously. A recent European Society for Gastrointestinal Endoscopy (ESGE) clinical guideline recommends use of CSP as the preferred technique to remove polyps $\leq 5 \mathrm{~mm}$ [7]. In a large scale clinical trial reported in 2013, incidence of delayed bleeding was zero for 1015 polyps $<1 \mathrm{~cm}$ [8]. However, this trial had only one treatment arm. To our knowledge, there have not been any randomized clinical trials (RCTs) to compare delayed bleeding rate as primary outcome or demonstrate any significant difference. In 2014, one prospective RCT was reported with a significantly lower rate of delayed bleeding after CSP [9]. However, the generalizability of this finding is limited because it was a single-center small-scale study $(n=70)$ with patients receiving anticoagulant therapy. Therefore, we conducted a multicenter RCT to compare rates of delayed bleeding after CSP and HSP.

\section{Patients and methods}

\section{Trial design}

We conducted a RCT in six centers (Aizu Medical Center, Takeda General Hospital, Fukushima Rosai Hospital, Hokkaido Gastroenterology Hospital, Saitama Medical Center, and Fujita General Hospital) in Japan. The study protocol followed ethical guidelines of the Helsinki Declaration, was approved by the Institutional Review Board at each institution and the trial registered with the University Hospital Medical Information Network (UMIN000012520). Enrollment occurred from September 2013 to June 2016. The CONSORT (Consolidated Standards of Reporting Trials) guidelines were followed in reporting this study.

\section{Participants}

Patients aged 20 to 80 years scheduled to undergo colonoscopic polypectomy and who provided informed consent were eligible for enrollment. Recruitment of qualified patients in this study focused on individuals with diminutive colon polyps ( $\leq 9$ $\mathrm{mm}$ ) detected during previous colonoscopy but who did not undergo endoscopic resection for various reasons, or patients referred to undergo polypectomy for diminutive colon polyps $(\leq 9 \mathrm{~mm})$. Pedunculated polyps were not excluded in this study. Exclusion criteria included: (1) patients with polyps measuring $\geq 10 \mathrm{~mm}$ in a previous colonoscopy; (2) patients unable to discontinue anticoagulants or antiplatelet therapy, according to the Japanese guidelines [10] or who had an existing hemorrhagic diathesis; (3) history of inflammatory bowel disease; (4) history of familial adenomatous polyposis; or (5) an apparently invasive colorectal cancer.

\section{Assignment}

Participants scheduled to undergo endoscopic polypectomy were enrolled and randomly allocated to CSP or HSP (allocation ratio $1: 1)$. Random allocation was performed by a research assistant using a computer-generated randomization sequence. Just before colonoscopy, the allocation was made known to the operator and the patients, using the telephone.

\section{Procedure}

Patients underwent standard bowel preparation beginning on the day prior to the procedure. In general, patients were not given sedation, but all were given an anticholinergic agent (butylscopolammonium bromide) or glucagon. If patients complained of severe pain or discomfort, sedation was administered at the endoscopists' discretion. Twelve operators performed the procedures, 11 of whom had a personal experience of $>2,000$ colonoscopies. Cecal intubation was confirmed either by ileal intubation or visualization of both the appendiceal orifice and the ileocecal valve. Quality of bowel preparation was assessed according to the extent of mucosal visualization after suction of any residual fluid, using the Aronchick Bowel Preparation scale [11]. After cecal intubation, the operator searched for polyps while withdrawing the endoscope. The operator performed the polypectomy by the allocated method (CSP or HSP). Regardless of allocation, the same snare wire (Captivator $13 \mathrm{~mm}$, Profile $27 \mathrm{~mm}$ ) was arranged in advance at each hospital, and snare wires dedicated to cold resection were not used in this study. The technique used was cold resection of the polyp without tenting and then suction of the transected polyp into a trap followed by histopathologic evaluation. An ERBE VIO300 (Amco, Tokyo, Japan) was used in the Endocut mode with the effect 3 current set at output limit $120 \mathrm{~W}$ and forced coagulation current set at an output limit of $35 \mathrm{~W}$ for HSP (conventional) polypectomy. Submucosal injection of saline before removal was not performed, regardless of the assignment. Hemostatic clipping was performed to stop active bleeding such as spurting or oozing that continued for more than one minute after polypectomy. Prophylactic clipping of resection sites was permitted at the endoscopists' discretion. Size, morphology and location of polyps were recorded. Within 1 month after polypectomy, all patients visited the outpatient clinic to be informed of the histology and to confirm any occurrence of delayed bleeding. Occurrence of any adverse events or gastrointestinal symptoms including perforation were recorded. 


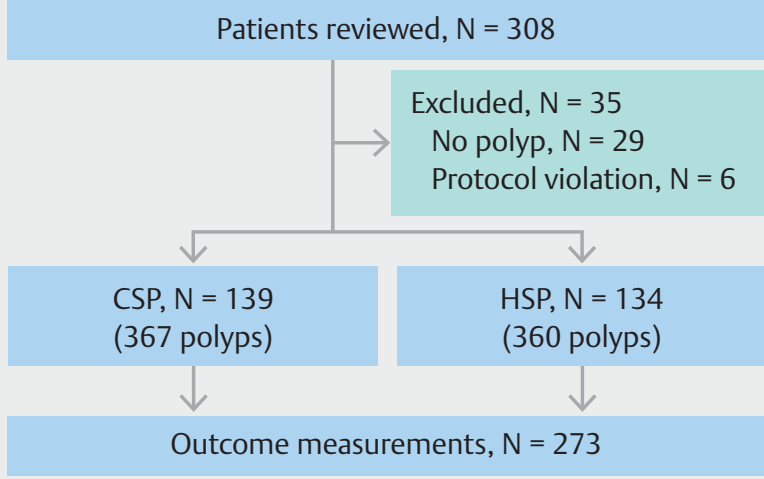

- Fig. 1 Study flow Diagram.

\section{Drop-outs}

The study was discontinued in patients: (1) who had no polyps measuring $\leq 9 \mathrm{~mm}$; (2) who had $\geq 10 \mathrm{~mm}$ polyps; (3) who had conversion of the resection method; (4) in whom total colonoscopy could not be accomplished; or (5) whose bowel preparation was poor.

\section{Outcome measures}

The primary outcome measure was rate of delayed bleeding at 24 hours or later after resection. Secondary outcome measures were the rate of immediate bleeding during the procedure, rates of prophylactic clipping, and early (within 24 hours) bleeding. Delayed or early bleeding was determined based on clinical history, regardless of achieving endoscopic hemostasis. A slight decrease in hemoglobin $(1 \mathrm{mg} / \mathrm{dL}$ or less) was not defined as bleeding. Immediate bleeding was defined as spurting or oozing that continued for more than 1 minute, regardless of clipping.

\section{Sample size calculation}

Sample size was calculated based on patient-based data from previous studies with a $0.1 \%$ bleeding rate using CSP, and a $2 \%$ bleeding rate using HSP for diminutive polyps ( $\leq 9 \mathrm{~mm})[4,8]$.
For the study to have $80 \%$ power at a significance level of $0.05,451$ patients were required in each arm. If the sample size does not reach this estimate by the end of the study period, an interim analysis is scheduled to decide whether to extend or terminate the trial. In this interim analysis, the study will be terminated if a $P$ value $<0.01$ or conditional power $<50 \%$ is determined at that time.

\section{Statistical methods}

All outcome measures, i.e. bleeding rates and clipping rates, were calculated with $95 \%$ confidence intervals $(\mathrm{Cl})$ using the Clopper-Pearson method and expressed as " $n$ [proportion, $95 \% \mathrm{Cl}$ ]" For nominal data, statistical comparisons were made using the chi-square test for equality of proportions. Patient demographic data and polyp characteristic data were calculated with a $95 \% \mathrm{Cl}$ using the Clopper-Pearson method and are expressed as "n [proportion, 95\% Cl]". For continuous data with a normal distribution, Student's t-test was applied. All $P$ values are two-tailed, and values $<0.05$ were considered to indicate statistical significance. All statistical analyses were performed with Stata $13.0^{\circledR}$ (Stata Corp., Texas, United States).

\section{Results}

\section{Interim analysis}

At the end of the study period (decided in advance), 308 participants were recruited from September 2013 to June 2016. To decide whether to extend the trial or to terminate the trial, we performed this interim analysis.

\section{Patients and polyps}

After 35 patients were excluded (29 had no polyps; 6 had protocol violation), 273 patients (mean age $62.2 \pm 8.8$ years; 188 males) were enrolled with 139 patients allocated to CSP and 134 patients to HSP. A total of 367 polyps were resected in CSP vs. 360 polyps in HSP ( $>$ Fig. 1). There were no significant differences in patient demographics between the two groups ( Table 1$)$. Characteristics of polyps removed were similar in both groups ( Table 2 ). Location and morphology showed slight deviations.

- Table 1 Patient demographics.

\begin{tabular}{|c|c|c|c|}
\hline & & $\operatorname{CSP}(n=139)$ & $\operatorname{HSP}(n=134)$ \\
\hline \multirow[t]{2}{*}{ Gender } & Female & $46(33.1,25.4-41.6)$ & $39(29.1,21.6-37.6)$ \\
\hline & Male & $93(66.9,58.4-74.6)$ & $95(70.9,62.4-78.4)$ \\
\hline \multirow[t]{4}{*}{ Age, years } & Mean \pm SD & $65.7 \pm 8.8$ & $66.7 \pm 8.8$ \\
\hline & $20-40$ & $1(0.7,0.0-3.9)$ & $0(0.0$, not applicable) \\
\hline & $41-60$ & $30(21.6,15.1-29.4)$ & $32(23.9,16.9-32.0)$ \\
\hline & $61-80$ & $108(77.7,69.9-84.3)$ & $102(76.1,68.0-83.1)$ \\
\hline
\end{tabular}


- Table 2 Characteristics of polyps.

\begin{tabular}{|c|c|c|c|}
\hline & & $\operatorname{CSP}(n=367)$ & HSP $(n=360)$ \\
\hline \multirow[t]{3}{*}{ Location } & Proximal colon & $191(52.0,46.8-57.3)$ & $152(42.2,37.1-47.5)$ \\
\hline & Distal colon & $137(37.3,32.4-42.5)$ & $154(42.8,36.7-48.1)$ \\
\hline & Rectum & $39(10.6,7.7-14.2)$ & $54(15.0,11.5-19.1)$ \\
\hline \multirow[t]{3}{*}{ Size, mm } & Mean \pm SD & $5.1 \pm 1.7$ & $5.2 \pm 1.9$ \\
\hline & $1-5$ & $233(63.5,58.3-68.4)$ & $224(62.2,57.0-67.3)$ \\
\hline & $6-10$ & $134(36.5,31.6-41.7)$ & $136(37.8,32.7-43.0)$ \\
\hline \multirow[t]{3}{*}{ Morphology } & $0-11 \mathrm{a}$ & $81(22.1,17.9-26.7)$ & $65(18.1,14,2-22.4)$ \\
\hline & 0 -Is & $274(74.7,69.9-79.0)$ & $291(80.8,76.4-84.8)$ \\
\hline & $0-I p$ & $12(3.3,1.7-5.6)$ & $4(1.1,0.3-2.8)$ \\
\hline \multirow[t]{9}{*}{ Histology } & Adenoma & $311(84.7,80.6-88.3)$ & $311(86.4,82.4-89.8)$ \\
\hline & - High-grade & $7(1.9,0.8-3.9)$ & $11(3.1,1.5-5.4)$ \\
\hline & - Low-grade & $302(82.3,78.0-86.1)$ & $295(81.9,77.6-85.8)$ \\
\hline & Mucosal cancer & $2(0.5,0.1-2.0)$ & $5(1.4,0.5-3.2)$ \\
\hline & Hyperplastic polyp & $26(7.1,4.7-10.2)$ & $28(7.8,5.2-11.0)$ \\
\hline & SSA/P & $6(1.6,0.6-3.5)$ & $3(0.8,0.2-2.4)$ \\
\hline & TSA & $2(0.5,0.1-2.0)$ & $2(0.5,0.1-2.0)$ \\
\hline & Leiomyoma & $1(0.3,0.0-1.5)$ & $0(0,0$, not applicable $)$ \\
\hline & Irretrievable polyp & $21(5.7,3.6-8.6)$ & $11(3.1,1.5-5.4)$ \\
\hline
\end{tabular}

- Table 3 Patient-based analysis.

\begin{tabular}{|c|c|c|c|}
\hline & \multicolumn{2}{|c|}{ Bleeding rates and clipping rate, $n$ (percentage, $95 \% \mathrm{Cl}$ ) } & \multirow[t]{2}{*}{$P$ value $^{1}$} \\
\hline & $\operatorname{CSP}(n=139)$ & HSP $(n=134)$ & \\
\hline Immediate bleeding & $88(63.3,54.7-71.3)$ & $38(28.4,20.9-36.8)$ & $<0.001$ \\
\hline Clipping & $48(34.5,26.7-43.1)$ & $49(36.6,28.4-45.3)$ & 0.725 \\
\hline Early bleeding & $0(0.0$, not applicable $)$ & $2(1.5,0.0-3.9)$ & 0.148 \\
\hline Delayed bleeding & $1(0.7,0.0-3.9)$ & $1(0.7,0.0-3.9)$ & 0.979 \\
\hline
\end{tabular}

\section{Patient-based analyses}

There were no significant differences in the early/delayed bleeding rates. In contrast, the rate of immediate bleeding was significantly higher in CSP, compared with HSP $(P<0.001)$ ( $\triangleright$ Table 3). However, rates of hemostatic clipping were almost the same in both groups.

\section{Polyp-based analyses}

The results were similar to the patient-based analysis $(\triangleright \mathrm{Ta}$ ble4). Except for immediate bleeding, there were no significant differences in bleeding rates or clipping rate. Using the number of polyps resected per-patient, a subgroup analysis was conducted ( $\triangleright$ Supplementary Table 1 ). The number of polyps resected per-patient did not affect the results. 


\begin{tabular}{|c|c|c|c|}
\hline & \multicolumn{2}{|c|}{ Bleeding rate and clipping rate, $n$ (percentage, $95 \% \mathrm{CI}$ ) } & \multirow[t]{2}{*}{$P$ value $^{1}$} \\
\hline & $\operatorname{CSP}(n=367)$ & $\operatorname{HSP}(n=360)$ & \\
\hline Immediate bleeding & $198(54.0,48.7-59.1)$ & $50(13.9,10.5-23.3)$ & $<0.001$ \\
\hline Clipping & $67(18.3,14.4-22.6)$ & $68(18.9,15.0-23.3)$ & 0.826 \\
\hline Early bleeding & $0(0$, not applicable $)$ & $2(0.6,0.0-2.0)$ & 0.153 \\
\hline Delayed bleeding & $1(0.3,0.0-1.5)$ & $2(0.6,0.0-2.0)$ & 0.552 \\
\hline \multicolumn{4}{|c|}{$\begin{array}{l}\mathrm{Cl} \text {, confidence interval; CSP, cold snare polypectomy; HSP, hot snare polypectomy. } \\
\text { Early bleeding rate: within } 24 \text { hours. Delayed bleeding rate: over } 24 \text { hours. } \\
{ }^{1} \text { Chi-square test }\end{array}$} \\
\hline
\end{tabular}

\begin{tabular}{|c|c|c|c|c|c|c|c|c|c|c|}
\hline $\begin{array}{l}\text { Lesion } \\
\text { no. }\end{array}$ & Group & $\begin{array}{l}\text { Early| } \\
\text { late }\end{array}$ & Age & Gender & Location & Morphology & Size & $\begin{array}{l}\text { Immediate } \\
\text { Bleeding }\end{array}$ & Clipping & Histology \\
\hline 1 & HSP & Early & 78 & male & distal & 0 -Is & $7 \mathrm{~mm}$ & Absent & No & $\mathrm{HP}$ \\
\hline 2 & HSP & Early & 59 & female & distal & 0 -Is & $4 \mathrm{~mm}$ & Absent & Done & LGA \\
\hline 3 & CSP & Late & 47 & male & proximal & 0 -Is & $9 \mathrm{~mm}$ & Present & Done & LGA \\
\hline 4 & HSP & Late & 73 & male & distal & 0 -IIa & $4 \mathrm{~mm}$ & Absent & Done & HGA \\
\hline 5 & HSP & Late & 73 & male & distal & $0-$ Is & $3 \mathrm{~mm}$ & Absent & Done & LGA \\
\hline
\end{tabular}
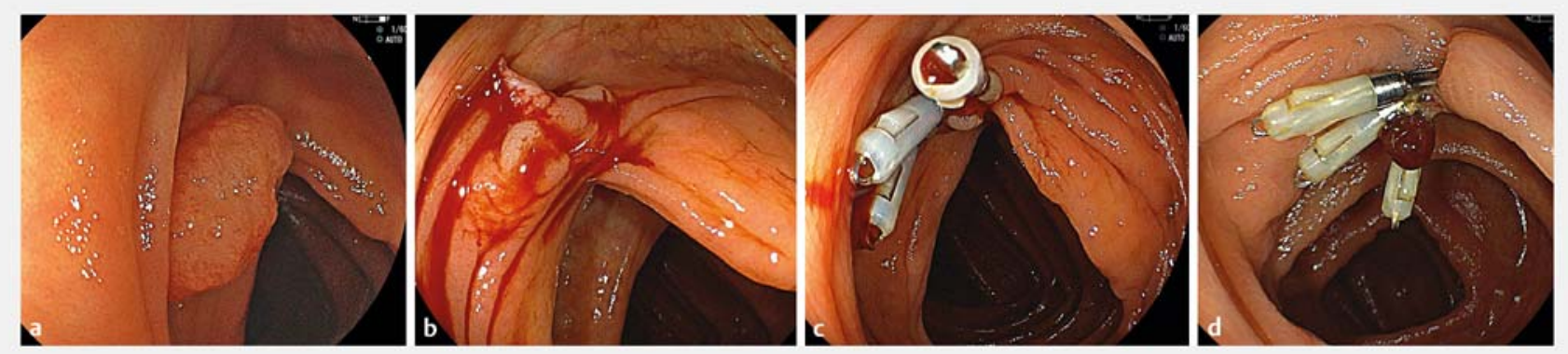

- Fig. 2 Delayed bleeding after cold snare polypectomy. a Colonoscopic image before polypectomy. b Immediate bleeding occurred just after resection. c Bleeding was successfully controlled with hemostatic clipping. d Ten days later, delayed bleeding occurred. A clot was observed between the clips.

\section{Bleeding}

- Table 5 summarizes details of procedures complicated by bleeding. Mean size of polyps associated with delayed bleeding was relatively large in the CSP group $(9 \mathrm{~mm})$ but smaller in the HSP group (three quarters were diminutive). After CSP, delayed bleeding occurred in only one lesion ( Fig.2a, $\mathbf{F i g . 2 b}$, $\checkmark$ Fig. 2c, $>$ Fig. 2 d). Bleeding occurred 10 days after resection, and was stopped immediately by hemostatic clipping. No blood transfusion was required.

\section{Discussion}

This study directly compared the delayed bleeding rates (primary outcome) after CSP and HSP, but did not show a statistically significant difference. We calculated conditional power to consider termination due to futility. Because the conditional power was $<50 \%(10.3 \%)$, we decided to terminate this clinical trial. We failed to prove the hypothesis that the delayed bleeding rate after CSP is lower than after HSP.

There are several reasons for the failure to demonstrate a difference. The overall delayed bleeding rate was much lower than expected, especially the delayed bleeding rate after HSP, which was much lower than in previous studies $(0.7 \%-2.0 \%)$ 
[4, 12 - 14]. The extremely low bleeding rate after HSP may be influenced by the open-label nature of this intervention. It is speculated that, in the HSP group, the snare may have been held more tightly closed, in a manner similar to CSP, and that electrocautery was applied for a shorter time, to reduce damage to the deep submucosal layer. Colonoscopists participating in this clinical trial may have unconsciously performed HSP more carefully than usual because they are aware that HSP is believed to cause more delayed bleeding than CSP.

The observed high rate of endoscopic clip application may be related to the low delayed bleeding rate. Generally, immediate bleeding after CSP stops spontaneously and does not require hemostatic clipping [6]. Hemostatic clipping is effective for control of immediate bleeding after polypectomy [15], but prophylactic use of hemostatic clips has not been proven to prevent delayed bleeding after conventional polypectomy [16-18]. In this study, however, the clipping rate was high (nearly $20 \%$ in both groups). Despite the low rate of immediate bleeding after HSP, the hemostatic clipping rate was the same as during CSP. Because prophylactic clipping at resection sites was permitted at the endoscopists' discretion, it may have been performed, regardless of presence of active bleeding.

An imbalance in polyp location and morphology could affect the low delayed bleeding rates, although an imbalance in morphology might be neglected due to a slight deviation. In contrast, polyps resected with CSP apparently deviated to the proximal colon. Several previous papers [19-20] stated that delayed post-polypectomy bleeding frequently occurred in the proximal colon. Conversely, one Japanese report [14] demonstrated almost the same rate of delayed bleeding. In the current series, one of the five polyps with delayed bleeding was in the proximal colon, implying that an imbalance in location would not greatly affect the results.

\section{Conclusion}

In conclusion, this interim analysis did not demonstrate that delayed bleeding after CSP is lower than after HSP. The delayed bleeding rate after HSP was much lower than expected.

\section{Acknowledgement}

The authors thank Ms. Jinko Kobayashi, Ms. Sanae Tanaka and Ms. Sumie Suzuki for administrative support.

Competing interests

None

References

[1] Winawer S], Zauber AG, Ho MN et al. Prevention of colorectal cancer by colonoscopic polypectomy. The National Polyp Study Workgroup. N Engl J Med 1993; 329: 1977 -1981
[2] Zauber AG, Winawer SJ, O’Brien M] et al. Colonoscopic polypectomy and long-term prevention of colorectal-cancer deaths. N Engl J Med 2012; 366: 687-696

[3] Gatto NM, Frucht H, Sundararajan V et al. Risk of perforation after colonoscopy and sigmoidoscopy: a population-based study. J Natl Cancer Inst 2003; 95: 230-236

[4] Heldwein W, Dollhopf M, Rosch T et al. The Munich Polypectomy Study (MUPS): prospective analysis of complications and risk factors in 4000 colonic snare polypectomies. Endoscopy 2005; 37: 1116 1122

[5] Anderson ML, Pasha TM, Leighton JA. Endoscopic perforation of the colon: lessons from a 10-year study. Am J Gastroenterol 2000; 95: $3418-3422$

[6] Tappero G, Gaia E, De Giuli P et al. Cold snare excision of small colorectal polyps. Gastrointest Endosc 1992; 38: 310-313

[7] Ferlitsch M, Moss A, Hassan C et al. Colorectal polypectomy and endoscopic mucosal resection (EMR): European Society of Gastrointestinal Endoscopy (ESGE) Clinical Guideline. Endoscopy 2017; 49: $270-297$

[8] Repici A, Hassan C, Vitetta E et al. Safety of cold polypectomy for $<10 \mathrm{~mm}$ polyps at colonoscopy: a prospective multicenter study. Endoscopy 2012; 44: 27-31

[9] Horiuchi A, Nakayama Y, Kajiyama M et al. Removal of small colorectal polyps in anticoagulated patients: a prospective randomized comparison of cold snare and conventional polypectomy. Gastrointest Endosc 2014; 79: 417-423

[10] Japan gastroenterological Endoscopy Society Guidelines. 2012

[11] Aronchick CA, Lipshutz WH, Wright SH et al. Validation of an instrument to assess colon cleansing [abstract]. Am J Gastroenterol 1999; 94: 2667

[12] Waye JD. Management of complications of colonoscopic polypectomy. Gastroenterologist 1993; 1: 158-164

[13] Sorbi D, Norton I, Conio M et al. Postpolypectomy lower GI bleeding: descriptive analysis. Gastrointest Endosc 2000; 51: 690-696

[14] Watabe $\mathrm{H}$, Yamaji Y, Okamoto M et al. Risk assessment for delayed hemorrhagic complication of colonic polypectomy: polyp-related factors and patient-related factors. Gastrointest Endosc 2006; 64: $73-78$

[15] Parra-Blanco A, Kaminaga N, Kojima T et al. Colonoscopic polypectomy with cutting current: is it safe? Gastrointest Endosc 2000; 51: $676-681$

[16] Shioji K, Suzuki Y, Kobayashi M et al. Prophylactic clip application does not decrease delayed bleeding after colonoscopic polypectomy. Gastrointest Endosc 2003; 57: 691-694

[17] Matsumoto M, Kato M, Oba K et al. Multicenter randomized controlled study to assess the effect of prophylactic clipping on post-polypectomy delayed bleeding. Dig Endosc 2016; 28: 570-576

[18] Boumitri C, Mir FA, Ashraf I et al. Prophylactic clipping and post-polypectomy bleeding: a meta-analysis and systematic review. Ann Gastroenterol 2016; 29: $502-508$

[19] Buddingh KT, Herngreen T, Haringsma J et al. Location in the right hemi-colon is an independent risk factor for delayed post-polypectomy hemorrhage: a multi-center case-control study. Am J Gastroenterol 2011; 106: 1119-1124

[20] Jaruvongvanich V, Prasitlumkum N, Assavapongpaiboon B et al. Risk factors for delayed colonic post-polypectomy bleeding: a systematic review and meta-analysis. Int J Colorectal Dis 2017; 32: 1399- 1406 
- Supplementary Table 1 Polyp-based subgroup analysis according to the number of polyps resected per-patient.

\begin{tabular}{|c|c|c|c|c|}
\hline & \multirow{2}{*}{$\begin{array}{l}\text { Number of } \\
\text { polyps resected } \\
\text { per-patient }\end{array}$} & \multicolumn{2}{|l|}{ Rate, n [percentage, $95 \% \mathrm{Cl}$ ] } & \multirow[t]{2}{*}{$P$ value $^{1}$} \\
\hline & & CSP & HSP & \\
\hline \multirow[t]{5}{*}{ Immediate bleeding } & 1 & $29 / 51(56.9,42.2-70.7)$ & $10 / 40(25.0,12.7-41.2)$ & 0.002 \\
\hline & 2 & $30 / 58(51.7,38.2-65.0)$ & $10 / 76(13.2,6.5-22.9)$ & $<0.001$ \\
\hline & 3 & $36 / 69(52.2,39.8-64.4)$ & $6 / 60(10.0,3.8-20.5)$ & $<0.001$ \\
\hline & 4 & $37 / 56(66.1,52.2-78.2)$ & $13 / 65(20.0,11.1-31.8)$ & $<0.001$ \\
\hline & $\geq 5$ & $66 / 133(49.6,40.8-58.4)$ & $11 / 119(9.2,4.7-15.9)$ & $<0.001$ \\
\hline \multirow[t]{5}{*}{ Clipping } & 1 & $12 / 51(23.5,12.8-37.5)$ & $13 / 40(32.5,18.6-49.1)$ & 0.341 \\
\hline & 2 & $16 / 58(27.6,16.7-40.9)$ & $10 / 76(13.2,6.5-22.9)$ & 0.036 \\
\hline & 3 & $14 / 69(20.3,11.6-31.7)$ & $16 / 60(26.7,16.1-39.7)$ & 0.392 \\
\hline & 4 & $11 / 56(19.6,11.7-32.0)$ & $18 / 65(27.7,18.2-39.6)$ & 0.301 \\
\hline & $\geq 5$ & $14 / 133(10.5,5.9-17.0)$ & $11 / 119(9.2,4.7-15.9)$ & 0.734 \\
\hline \multirow[t]{2}{*}{ Early bleeding } & 1 & 0/51 (0, not applicable) & $1 / 40(2.5,0.0-13.2)$ & 0.256 \\
\hline & $\geq 2$ & 0/316 (0, not applicable) & $1 / 320(0.3,0.0-1.7)$ & 0.320 \\
\hline \multirow[t]{2}{*}{ Delayed bleeding } & 1 & $1 / 51(2.0,0.0-10.4)$ & 0/40 (0.0, not applicable) & 0.373 \\
\hline & $\geq 2$ & 0/316 (0, not applicable) & $2 / 320(0.6,0.0-2.2)$ & 0.159 \\
\hline
\end{tabular}

